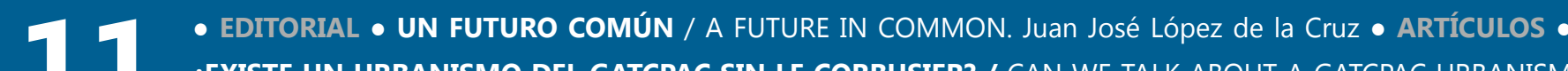
¿EXISTE UN URBANISMO DEL GATCPAC SIN LE CORBUSIER? / CAN WE TALK ABOUT A GATCPAC URBANISM WITHOUT LE CORBUSIER'S INFLUENCE? Roger Joan Sauquet Llonch • ODAM - A CONSTRUÇÃO DO MODERNO EM PORTUGAL: ENTRE O UNIVERSAL E O SINGULAR / ODAM - THE CONSTRUCTION OF THE MODERN IN PORTEAL BETWEEN UNIVERSAL AND SINGULAR. Edite Maria Figueiredo e Rosa • LA SILLA DEL GATEPAC: UN VIAJE COLECTIVO DE IDA Y VUELTA / THE GATEPAC CHAIR: A COLLECTVE JOURNEY THERE AND BACK AGAIN. Maria Villanueva Fernández; Héc. tor Garcí-Diego Villarias $\bullet$ EL ESPACIO INTERMEDIO Y LOS ORíGENES DEL TEAM $X /$ The Space Between and the origins of Team X. Antonio Juárez Chicote; Fernando Rodríguez Ramirez • PENSAMIENTOS COMPARTIDOS. ALDO VAN EYCK, EL GRUPO COBRAYEL ARTE/SHARED THOUGHTS. ALDOVANEYCK, THE COBRA GROUP, AND ART. Esther MayoralCampa •CLAUDE PARENT EN NUEVA FORMA: LA RECEPCIÓN DE ARCHITECTURE PRINCIPE EN ESPAÑA / CLAUDE PARENT AT NUEVA FORMA: THE READING OF ARCHITECTURE PRINCIPEIN SPAIN. Lucía C. Pérez Moreno • CONSTRUYENDO UNA UTOPIE AUTRE IAMAZING ARCHIGRAM!-50 AÑOS DEZOOM!/ZZZZZRRTT//THUD!/ BLAAM!] / BUILDING AUTOPE AUTRE [AMAZING ARCHIGRAM!- 50 YEARS OF ZOOM!/ ZZZZRRTT// THUD:/ BLAAMI]. Luis Miguel Lus Arana • TAN CERCA, TAN LEJOS: ALDO ROSSI Y EL GRUPO 2C. ARQUITECTURA, IDEOLOGÍA Y DISIDENCIAS EN LA BARCELONA DE LOS 70 / SO CLOSE, SO FAR: ALDO ROSSI AND THE2C GROUP. ARCHITECTURE, IDEOLOGY AND DISSENTS IN THE BARCELONA OF THE 70S. Carolina Beatriz García Estévez • RESEÑAS BiBLIOGRÁFICAS• G. ASPLUND, W. GAHN, S. MARKELUUS, G. PAULSSON, E. SUNDAHL, U. AHRÉN: ACCEPTERA. Pablo López Santana

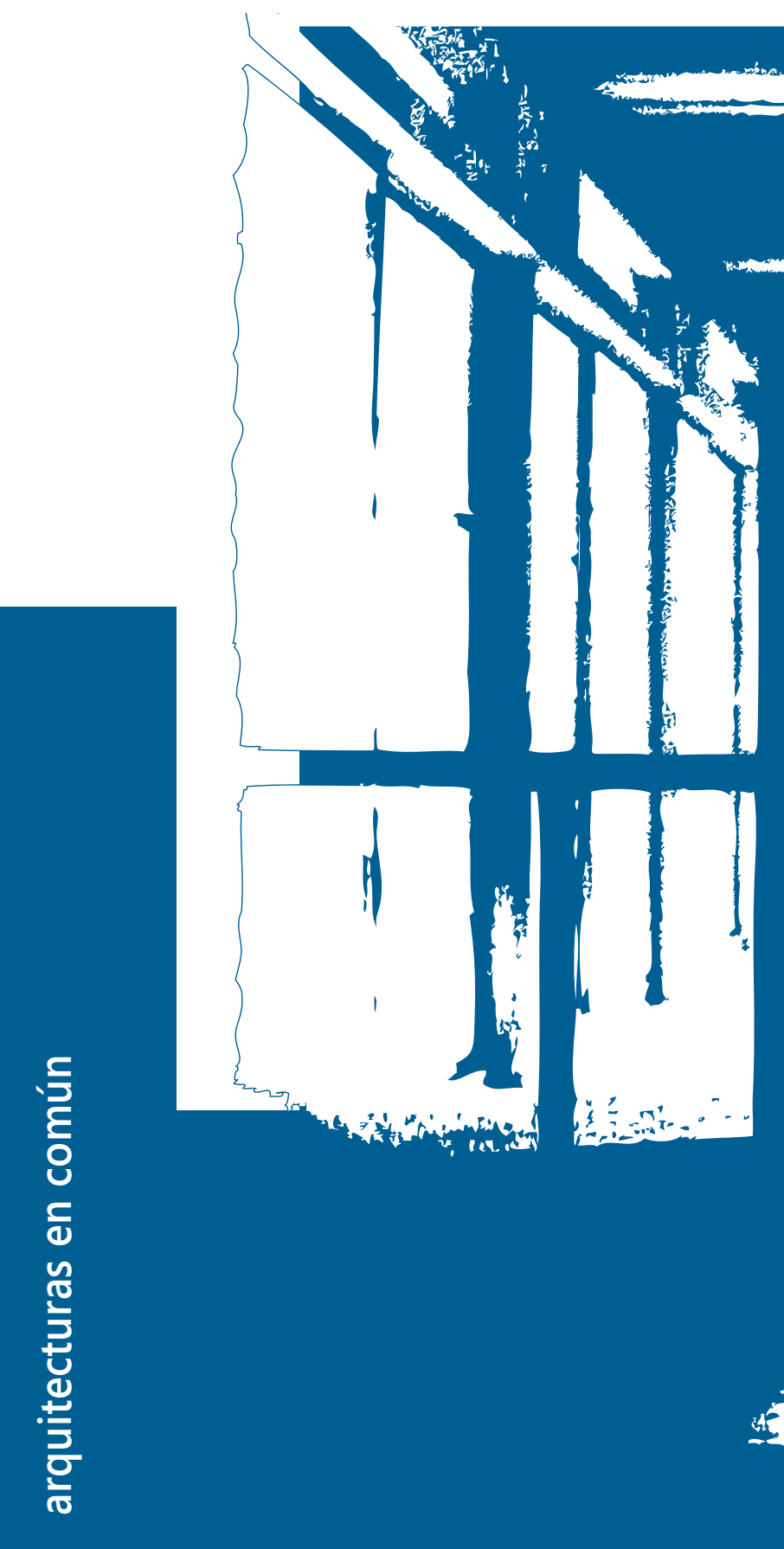

制 20 $t^{\prime \prime 2}$

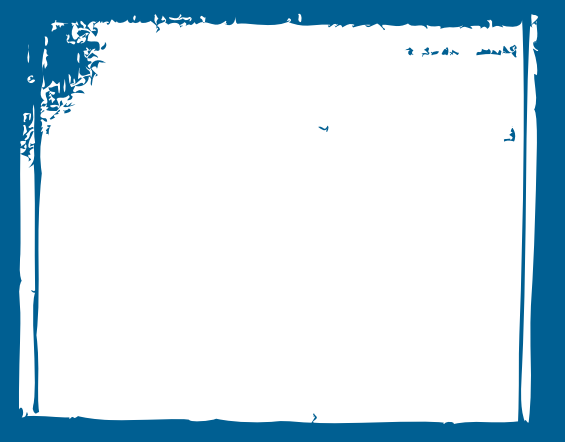

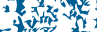

ARQUITECTURAS EN COMÚN

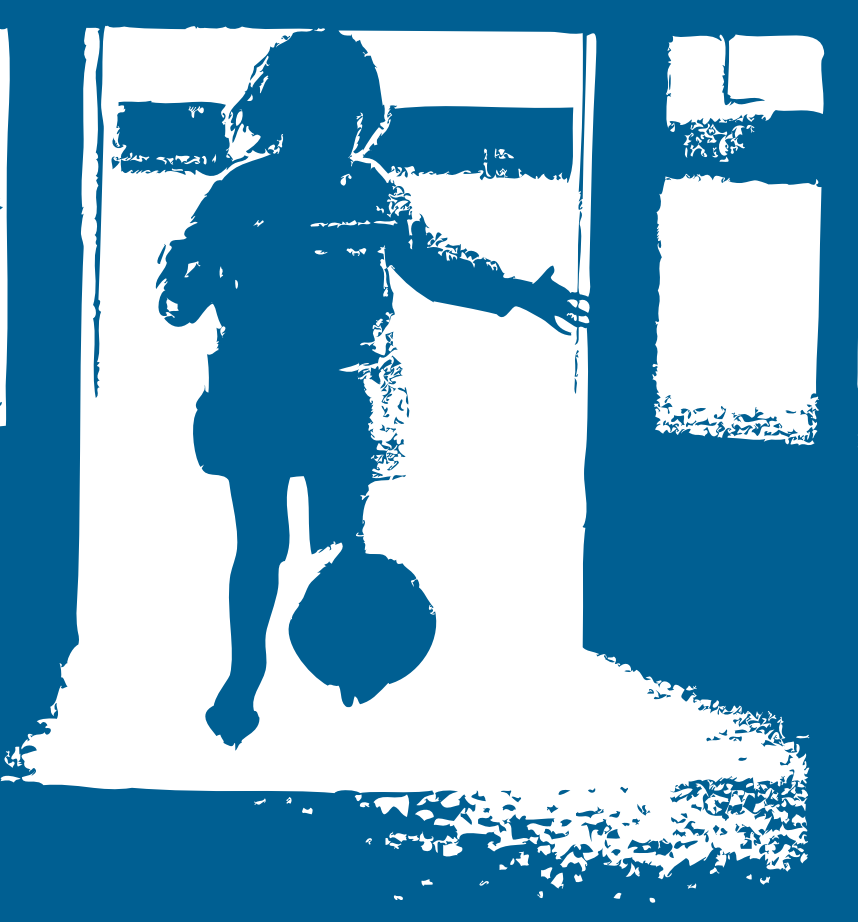

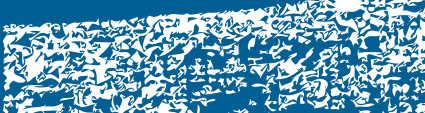

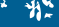
tation 
¿EXISTE UN URBANISMO DEL GATCPAC SIN LE CORBUSIER? / CAN WE TALK ABOUT A GATCPAC

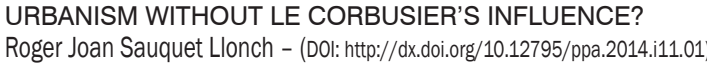

ODAM - A CONSTRUÇÃO DO MODERNO EM PORTUGAL: ENTRE O UNIVERSAL E O SINGULAR I ODAM - THE CONSTRUCTION OF THE MODERN NN PORTUGAL: BETWEEN UNIVERSAL AND SINGULAR

LA SILLA DEL GATEPAC: UN VIAJE COLECTIVO DE IDA Y VUELTA / THE GATEPAC CHAIR: A

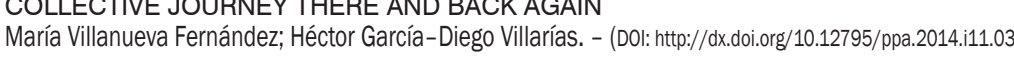

EL ESPACIO INTERMEDIO Y LOS ORÍGENES DEL TEAM X / THE SPACE BETWEEN AND THE

Antonio Juárez Chicote; Fernando Rodríguez Ramírez - (Do: htrp://dx.do.orgrg 10.12795/ppa.2014.11.04)

PENSAMIENTOS COMPARTIDOS. ALDO VAN EYCK, EL GRUPO COBRA Y EL ARTE / SHARED THOUGHTS. ALDO VAN EYCK, THE COBRA GROUP, AND ART

CLAUDE PARENT EN NUIVA FORMA: LA RECEPCIÓN DE ARCHIICTURE PR

PRINCIPE IN SPAIN

CONSTRUYENDO UNA UTOPIE AUTRE [AMAZING ARCHIGRAM! - 50 ANOS DE ZOOM!/ ZZZZRRTT!: THUD!/ BLAAM!] / BUILDING A UTOPIE AUTRE [AMAZING ARCHIGRAM! - 50 YEARS OF ZOOM!/ ZZZZRRTT!/ THUD!/ BLAAMI!

TAN CERCA, TAN LEJOS: ALDO ROSSI Y EL GRUPO 2C. ARQUITECTURA, IDEOLOGÍA Y DISIDENCIAS EN LA BARCELONA DE LOS 70 / SO CLOSE, SO FAR: ALDO ROSSI AND THE $2 C$

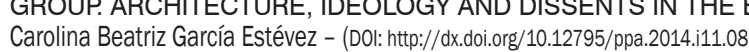




\section{LA SILLA DEL GATEPAC: UN VIAJE COLECTIVO DE IDA Y VUELTA}

THE GATEPAC CHAIR: A COLLECTIVE JOURNEY THERE AND BACK AGAIN

Marí Villanueva Fernandez; Héctor García-Dieso V Vilarís

RESUMEN Como resultado crítico derivado de la valoración del mueble entre 1880 y 1930, el GATEPAC estableció algunos parámetros definitoriosi irrenunciables que condicionaban la determinación del mobiliario moderno -honestidad, coherencia y fun-
ción, principalmente-, y que estaban en consonancia con las ideas defendidas por arquitectos teóricos relevantes del periodo. Respondiendo a estos tres aspectos básicos, el grupo elaboró una caracterización del mueble moderno, el cual, a su juicio, debía

ser: simple, ligero, transportable, higiénico y estándar.
Conforme a stos aspectos, los arquitectos del GATEPAC desarrollaron desde finales de los años 20 y hasta 1936 un conjunto de
sillas estándar que sirvieron como objeto de experimentación de las reflexiones del grupo. Estas piezas surveren una evolución sillas estándar que sirvieron como objeto de experimentación de las reflexiones del grupo. Estas piezas sufrieron una evolución
desde el mueble de acero hasta el mueble de madera y mimbre -el mueble popular. En este desarrollo permanecieron vigentes los principios alcanzados en la modermidad, pero las formas y materiales fueron transformados. Es en estos útimimos aspectos donde ese progreso puede entenderse como una evolución inversa en la que, una vez conseguida la liberación del mobiliario de lo decorativo e inútil, se regresa hacia unas formas y materiales propias del universo popular. SUMMARY As a critical result of furniture valuation between 1880 and 1930 , the GATEPAC group set a number of invariable
parameters that conditioned the definition of modern furniture (honesty, consistency and function were the primary values), in line with the ideas advanced by significiant architecture theorists at that time. In light of these three basic criteria, the GATEPAC group
wation developed a view of modern furniture as being simple, lightweight, portable, hygienic and standard.

In line with these criteria, the GATEPAC architects experimented with the production of a standard set of chairs between the late 1920s and 1936. These pieces evolved from steel to wood and wicker design - popular furniture. Atthough the established princi that progress may be read as a form of reversed evolution, whereby no longer required to be merely decorative and useless. furniture design was free to return to forms and materials of the popular domain.
KEY WORDS GATEPAC; furniture, modernity; standard; popular.

Persona de contacto/Corresponding autor: mvillanuev@@unav.es Escuela Técnica Superior de Arquitectura. Universidad de Navarra
LA SILLA DEL GATEPAC

a silla fue uno de los elementos predilectos elegidos por los miembros del GATEPAC para experimentación. El interés se justificaba en sus condicionantes fisicos: la relación directa con el cuerpo humano, la desvinculación física con la arquitectura-que permitia poner a prueba de un modo menos comprometido los ultimos avances técnicos-y su carácter predominantemente funcional e iconico hicieron de este mueble un magnifico tubo de ensayo.

El objetivo de obtener pitzing coherentes y funcionales, basadas en los principios de ligereza, movilidad e higiene, llevó a los arquitectos de GATEPAC a crear una colección de sillas estândar que fue a la postre, testimonio de un revelador recorido intelectual de iday vuetta. De modo que a través de la silla es posible analizar cômo se adoptó en primer lugar el mueble de acero como paradigma, para luego ser reemplazado por el mueble de maderay mimbre.

va. Mientras que resulta complicado desligar el ejercicio

ordinario de la profesión de arquitecto de la labor del propio autor, el diseño de mobiliario, por su escala, margen presupuestario y mayor laxitud en otros condicionantes, se presta, de un modo más adecuado, a proponer un proyecto comín respecto a unos determinados principios. Hasta el punto de que, más allá de buenos propósilos, los milmbros de glupo dan canta de nasuraza a este fin mediante la regulación de su propio trabajo en materia de diseño de mobiliario.

Según explica el documento "Exposició Mobles Model GATCPAC" encontrado en el Arxiu Històric del Col-legi d'Arquitectes de Catalunya, los muebles creados según modelos dibujados por los socios de la agrupación -0 bien por otros proyectistas- debian ser catalogados y denominados "Mobles Model GATCPAC". Para ello, debian ser aprobados por una Comisión de Control, nombrada por la junta e integrada por dos elementos directivos del GaTCRAC y uno de la sociecad "Mobles Model GATCPAC". No solo esto, incluso los beneficios derivados de su comercialización eran compartidos entre los diseñadores particulares de cada pieza y la colectividad'.

1. Según este documento el GATCPAC percibía un $5 \%$ sobre el precio de venta del mueble por concepto de alquiler del local y de utilización del personal y el proyectista un $5 \%$ de dicho importe en concento de honorarios por su trabaio Además, en el texto se establecín las condiciones de producción entre otros aspectos. 


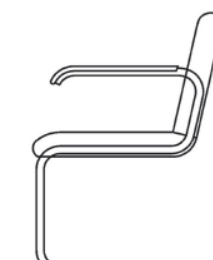

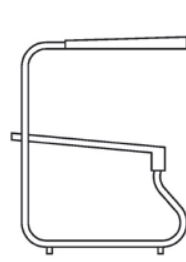

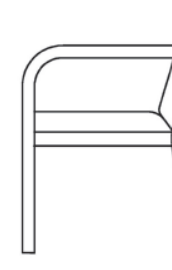

sino de la asimilación y correcta digestión de los principios promulgados por el empuje de la modernidad.

Un recorrido que, además, puede ser interpretado en clave de autoría: mientras que los primeros diseños, en tubo de acero fundamentalmente, se fijaban en la obra personal de algunas de las figuras más descollantes del panorama arquitectónico culto internacional, las obras más tardías, aquellas que tomaban como modelo el estándar popular, reparaban en el saber secular compartido de la tradición vernácula. De modo que, en uno de los extremos de este viaje, se tiene una preeminencia clara de la autoría individual de la obra, mientras que en el otro, el conocimiento acumulado por el paso de generaciones no puede ser atribuido a la mente de un creador concreto. Con lo que esta manera natural de hacer sólo puede ser heredada como un proyecto intelectual que en este caso, asume como propio el GATEPAC. Así lo exponía el grupo en su revista A.C.: "El mobiliario popular, sin pretensiones estilísticas, es, como la arquitectura popular, un buen ejemplo del espiritu que debe animar la construcción de los muebles de hoy. La emoción del mueble popular proviene de su proporción humana, de su simplicidad, de no pretender ser algo trascendental. Este espiritu con otra técnica es digno de imitarse"t.

Pero además, acercarse al caso de la silla es si cabe aún más revelador. De hecho, Esta evolución crítica es protagonizada -como ya se ha dicho- por el mueble de asiento, que materializa las reflexiones y pensamientos del grupo acerca del mueble moderno. El mueble de asiento se erige como objeto experimental del proceso evolutivo, de tal modo que puede considerarse que cada una de las piezas diseñadas por los integrantes de la agrupación milita en el mismo proyecto intelectual. Hasta el punto de que todas ellas forman parte de una. la silla del GATEPAC, basada en los principios de ligereza, higiene, y simplicidad según las necesidades de su usuario y la arquitectura en la que se ubica (figura 1).
ACERO

El tubo de acero fue recibido entusiastamente por los futuros miembros del GATEPAC. A diferencia del mueble $d e$ madera maciza, el mobiliario de tubo de acero ocupaba menos espacio - debido a las características resistentes del material que permitian reducir las secciones estructurales ante iguales solicitaciones-, diluyéndose en el ambiente debido a su carácter inmaterial. Como diría Walter Gropius, "No es otra cosa que un encuentro de coordenadas, un abstracto lugar espacial al que la presencia de la persona dará vida y concreción $(. . .)^{\text {ns. }}$. De modo que las posibilidades que ofrecía este material rápidamente pasaron a formar parte de las inquietudes de algunos de los arquitectos del GATEPAC, como Josep Torres Clavé José Manuel Aizpurua y Joaquín Labayen.

No obstante, en un principio, la producción mediante esta técnica era de por sí más que meritoria en la época. En Madrid, por ejemplo, la firma Mac (Muebles de ace curvado) de José María Fernández de Castro y Eduardo Shaw Loring, comenzó construyendo estas piezas con medios artesanales, rellenando el perfil tubular con plomo y arena, hasta que consiguio importar una máquina especializada para este trabajo 6 . En Cataluña sucedía algo similar: algunos muebles de tubo de acero curvado -incluyendo mesas, camas, armarios y vitrinas- eran en realidad producto de la habilidad de algunos de los mejores artesanos, en complicidad con pequeñas empresas, como Hermann Heydt, o, en Barcelona, Vda. J. Ribas y Casa Buades, S.A.

A pesar de las dificultades, los arquitectos miembros del emblemático grupo fueron partidarios, al comienzo,

5. Argan, Giulio Carlo: Walter Gropius y el Bauhaus. Buenos Aires: Nueva Visión, 1961. p.57.

6. Cfr. Blasco Castiñeira, Selina: Luis Feduchi 1901-1975, Monograffias de arquitectos españoles. Dirección General de Arquitectura, MOPu.

7. Cfr. Torres Torres, Raimon y otros: Josep Torres Clavé. Barcelona: Santa \& Cole, 1994. p.18.

8. La mesa se caracterizaba por la descomposición de los elementos que la definian -zona de trabajo acristalada y unidad de cajones exento. La estructura del mueble era mixta, de hierro y madera, y se correspondía con las partes que componen el conjunto. 9. Torres Torres, Raimon y otros, op. cit., p.19.

10. Ibíd, p.18.

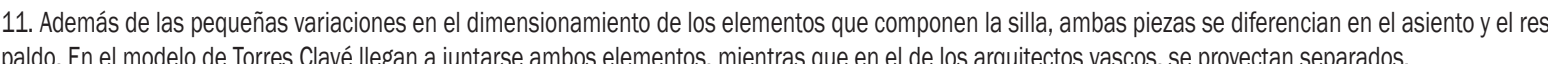




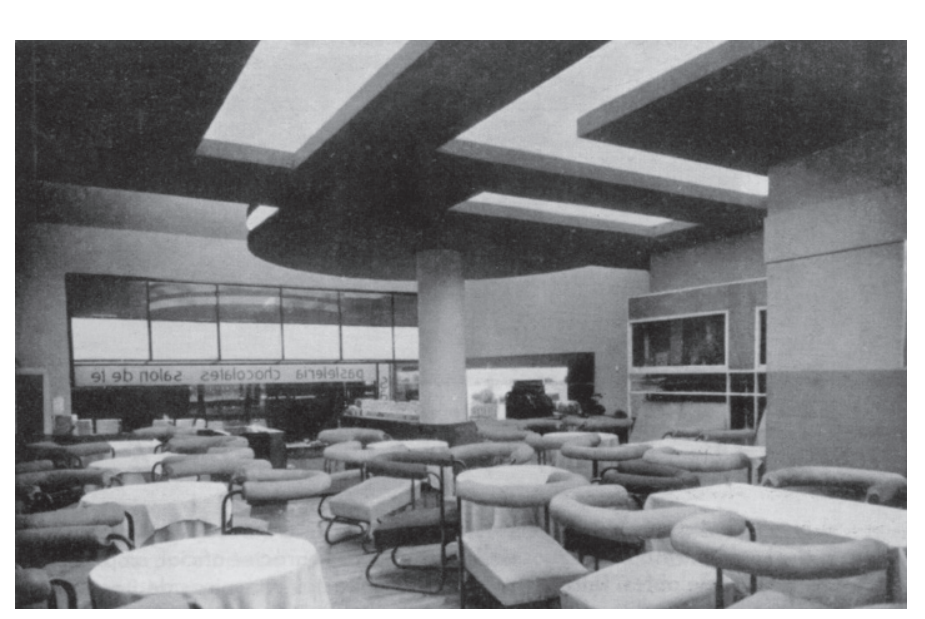

. Fotografía del interior de la Pastelería Sacha. 3. Factura y correspondencia de Damaso Azcue ditgidas al Grupo Este del GATEPAC, 1933. 4. Silla de la Joyería Roca y sillón Standard.

estudio. Ambos modelos guardan un asombroso parecido con la silla Cesca de Marcel Breuer.

Precisamente, Aizpurua y Labayen, al igual que los anteriores, fueron seducidos por el lenguaje del mobiliario procedente de la vanguardia más racionalista. En el verano de 1929 inauguraron el Real Club Náutico de San Sebastián, en el que la pareja de arquitectos introdujo muebles en serie de la casa Thonet, entre los que se encontraban las silla MR10 del arquitecto Mies van der Rohe. Aunque en este proyecto la intervención de los arquitectos con respecto al moblaje se limitaba exclusiva mente a la selección de piezas, tan sólo un año después pudieron experimentar en el diseño de este tipo de mobiliario vanguardista.

En marzo de 1930, fue inaugurada la Pastelería y Sa lón de Degustación Sacha. El proyecto, que había sido encargado a los arquitectos vascos por Alejandro Barre neche -amigo de Aizpurua-, fue la oportunidad de proyectar mobiliario de tubo de acero de formas vinculadas con las corrientes europeas (figura 2). Aizpurua y Labayen, quienes consideraban que la elección y adecuación del mobiliario constituía una parte fundamental de la intervención, idearon un modelo de sillón que se adecuaba las distintas zonas definidas en el proyecto en función de material de tubo de acero con asiento, respaldo y brazos mullidos en el interior, y mimbre para ocupar la terraza exterior. La firma Dámaso Azcue, situada en Azpeitia12 la empresa encargada de la producción de la silla Sacha Conviene aclarar que, a pesar de que la Pastelería Salón de Degustación Sacha fuera inaugurada siete me-

ses antes de la formación del grupo, el diseño del sillón de Aizpurua y Labayen formó parte, al igual que la silla de Torres Clavé, del mobiliario del GATEPAC. El modelo de los arquitectos vascos se comercializó en el local de GATCPAC como así lo demuestran las facturas recogidas en el Arxiu Histôric del Collegi d'Arquitectes de Catalunya que la empresa ejecutora -Dámaso Azcue- emitió al grupo (figura 3). Además, se encuentran en el Arxiu recibis de la empresa de las piezas que habían vendido y el nombre de cada uno de sus compradores. El conjunto de documentos recopilados demuestran el gran éxito comercial que tuvo el modelo Sacha entre la sociedad de aquella época

Los dibujos de la silla Sacha realizados por la pareja de arquitectos -que se encuentran hoy en el Archivo Labayen- desvelan el interés de sus autores por crear formas vinculadas con la vanguardia con materiales como el acero y el mimbre. Prueba de ese interés generalizado propio del contexto de la época es el parecido que manifiesta respecto a varias piezas que se encontraban en el mercado en aquel momento, como la silla modelo SS33 de Anton Lorenz realizado en 1928 por la casa Desta Thonet, la W21 comercializada por la empresa Pel, o la silla Lariana con la que Giuseppe Terragni amuebló la Casa del Fascio en 1936. No obstante, el ejemplo más significativo en esta relación por su semejanza con el modelo Sacha es el que realizaría Feduchi para amueblar la película "El bailarín y el trabajador" en 1936, y que, curiosamente, compartiría escenario con otra de las sillas del

\section{La autoria se ha puesto en contacto con la empressa Damaso Azzue, y atirman no poseer ninguun documento ni plano de ese periodo. Conversacion man-
tenida en diciembre de 2011 .}

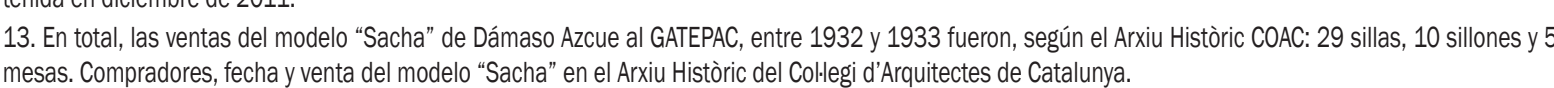




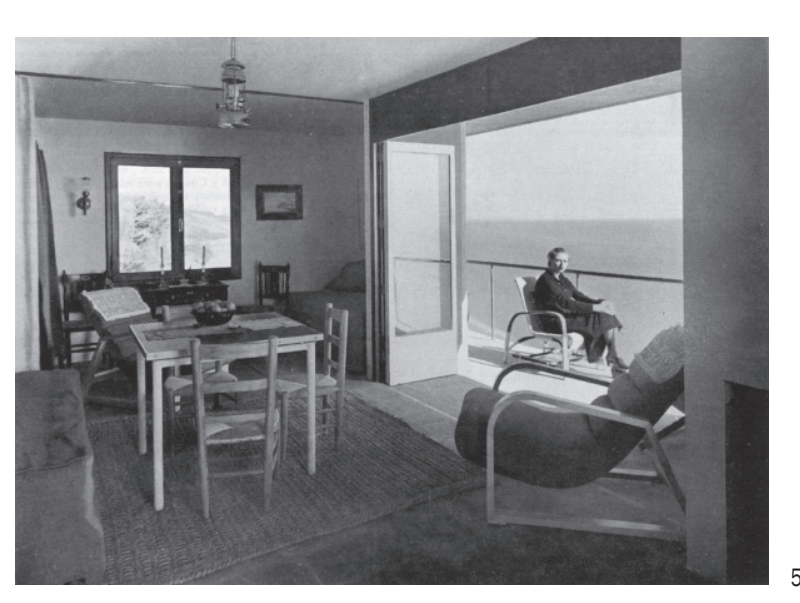

5. Fotografifía del interior de las viviendas de Garraf

6. Artículo de la revista Viviendas dedicado a los muebles de mimbre en el que se encuentran piezas 7. Estand per Grich Diecknann.

7. Estand del Grupo Este del GATEPAC para la Feria
de muestras de Barcelona de 1933 .
Este mueble fue uno de los más representativos del grupo en aquel momento. Al igual que el de la Joyer Roca fue construido por Vda. J. Ribas. Los anuncios de esta firma tomaron como imagen esta pieza y comenzaron a difundirse en diez números de la revista A.C. -a partir del número 4 hasta el 13 inclusive. Esta pieza, tambié de madera, proponía un aspecto nuevo en la tipología de mueble diseñada hasta el momento por el grupo: se trataba de un mueble formado por elementos desmontables, fáciles de armar.

El sillón protagonizó el artículo "Elementos 'Standard' en el mobiliario"20. $Y$ es que este mueble era claro heredero de las virtudes del mueble 'maquinista'. Su sencillez y su concepción basada en la suma de elementos estándar que configuran un todo, también estándar, constituian la prueba de la adaptación de los preceptos modernos de los 20 aplicados a muebles más confortables

En 1935, una vez formado el MIDVA, Torres Clavé realizó un modelo que combinaba referencias de este últmo mueble y del sillon que había diseñado para la casa de su hermana Rosa. Esta pieza, tal y como la describe su hijo Raimon Torres, se componía de una "disposición exenta de los elementos de soporte a base de brazos de madera y su asiento de somier tapizado con la posibilidad de presentarse en varias posiciones" ${ }^{\prime 21}$. Este mueble fue concebido para su instalación en las vivendas minimas para fin de semana en Garraf22 (figura 5).

20. GATEPAC: “Elementos 'Standard' en el mobiliario: Sillón de madera”. En A.C. Cuarto Trimestre 1931, No4. Barcelona. p. 21 21. Torres Torres, Raimon y otros, op. cit, p.19.

22. Ídem.

25. Dieckmann, Erich: "Möbelbau". En Die Baubücher. 1931, No11. Stuttgart: Julius Hoffmann Verlag. pp. 56-59.

el año 1932 el GATEPAC incorporó entre las piezas de su catálogo un sillón fabricado por la casa Dámaso Azcue de Azpeitia, en el Pais Vasco. El diseño fue ofrecido por Aizpunay Labayen, tal y como lo afirma el primero en una tentraba el local:" os mando unos modelos de sillas de

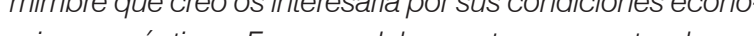
Q en precios verdaderamente económicos"zs. En una carta pre(ia, Azpurua habla anunciado al Grupo Este la posibilidad

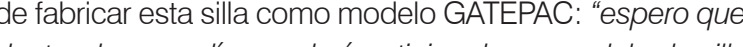
政 政 Apacio como modelo GATEPAC muy interesante" ${ }^{224}$. A parecib entonces en varios interiores diseñados por grupo una silla conformada por una estructura de madera recubierta de mimbre, y unos apoyabrazos que dipalas traseras y delanteras. Estas piezas se unian en la thictura. El astento estaba construido de palma trenzada esparto o enea. La silla guardaba un increible parecido pular y material con la diseñada por Erich Dieckmann, publicada en Mobelbau de Julius Hoffman en Stuttgart a principios de la decada de $1930^{25}$. En esa misma década, la silla de Dieckmann también fue difundida en varias de Torres Clavé y Sert, 1935

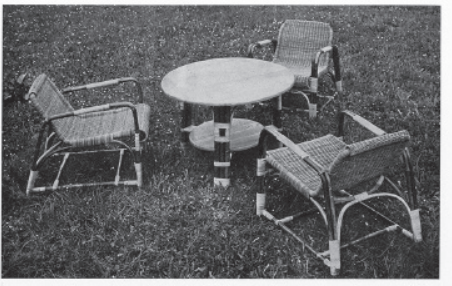

MUEBLS DE JUNCO $Y$ TUBO DE ACEO

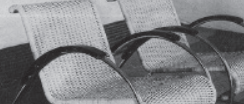

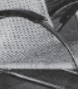
$=$

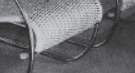

洒

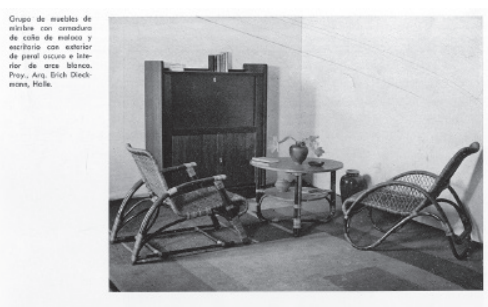
de las carlas que envió a la sede del GaTCPAC donde se que el mueble de mimbre en este pais se puede lograr a bujaban una curva en forma de U invertida que hacía de parte inferior con cuatro elementos que rigidizaban la es- ocasiones por revistas españolas como Viviendas, en artículos como "unco y acero" o "Muebles de junco y tubo de acero"26 (figura 6).

Esta silla resumía a perfección los valores aresanales de la simplicidad y la higiene que el grupo defendía Por esa razón, fue elegida por la agrupación al menos en tres ocasiones distintas para amueblar interiores de viviendas y exposiciones. En 1933, fue empleada como parte del mobiliario expuesto en la IV Feria de Muestras de Barcelona áa que el GATEPAC (ngura 7) concurrío en oolaboración con un gran número de empresas industriales. "muebles publicado por A.C. se explica que se trataba de "TEPAC por Dám por por el miembro del grupo Juan Baulista Subiana para el cho de culo realizado por Rosa Maŕa Subiana i Torrentzo como Por úllimo se encuentra on elAniu Historic del COAC .

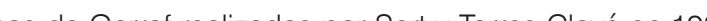

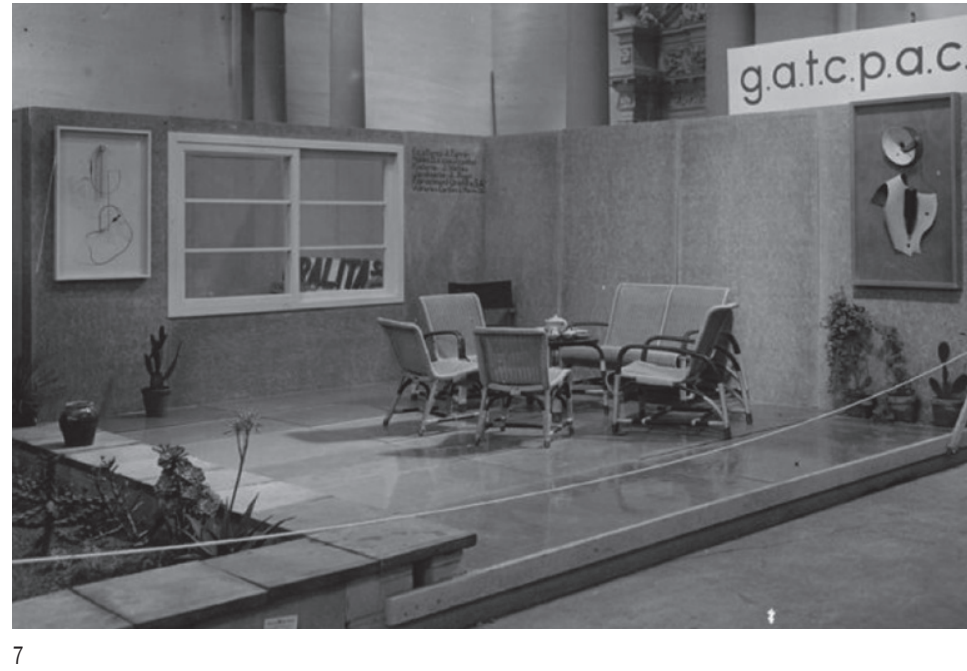

Es precisamente en este año cuando la revista A.C. publicó el artículo "Elementos de la industria popular" para confirmar y poner en valor algunos aspectos de la artesanía popular ya asentados en las conciencias de los arquitectos del grupo. El GATEPAC reclamaba la valoración de los objetos populares de uso doméstico, sin

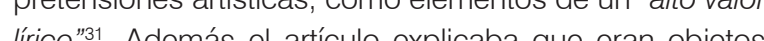
funcion ales el ariculo explicaba que eran objelos funcionar que se adaptaban a las caracteristicas de

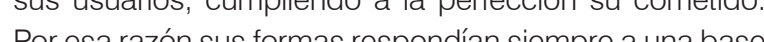

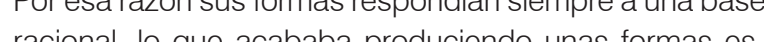
tándar que se reperion instentem do unas tormas es-

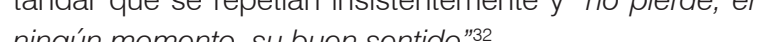
ingin

EGupo Este buscó en este concepto general de mue-

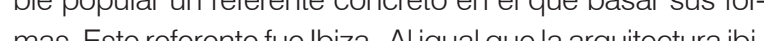
mas. Estereferente fue liziza. Angual que la arquilectura ibiy en especial los del GATCPAC, el mobillario de la isla

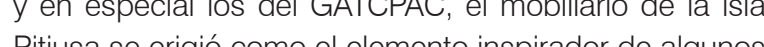
26. "Junco y acero". En Viviendas. Revista del Hogar. 1932, №5. Madrid. pp. 32-33; "Muebles de junco y tubo de acero". En Viviendas. Revista del Hogarar.
1935, №37. Madrid. pp.28-29.

27. El articulo publicado en la revista A.C. expone hasta en seis ocasiones que es el GATEPAC quien participa en la exposición, y tan solo en una de ellas se especcifica G.E (Grupo Este). Sin embargo, en las imagenenes de la muestra el estand es presidiao por un letrero en el que se puede leer GATCPAC.

28. GATEPAC: “Sección de noticias". En A.C., Segundo Trimestre 1933, No10. Barcelona. p.40.

29. Subirana i Torrent, Rosa Maŕa: "EI mobiliario del GATCPAC. Joan Baptista Subirana i Subirana interioristay diseñador de muebles". En DC. Revista de critica arquitectonica, 2005, $N$ 13 14. Barcelona. Universidad Politecnica de Catalunana, Departament de Composicio Arrquitectónica. pp.110-119.

30. En el Arxiu Histotoric del COAC se ha encontrado un documento de la empresa Dámaso Azcue del 12 de Diciembre 1934 que dice: "He reclbído de Don Juan B. Subiriana la cantidad 1 sofá... 155 Pts.".

31. GATEPAC: "Elementos de la industria popular" En A.C. 1935, N18. Barcelona. p.39.

32. GATEPAC: "La evolución del interior", op. cit, p.16.

33. Arquitectos como Germán Rodríguez Arias, Josep Luís Serty E Erwin Broner impulsaron la reivindicación de la arquitectura mediterénea tradicional ibicenca. Cfr. Freixa, Jaume, op. cit;; A.C. Segundo Trimestre 1935, NN18; Hausmann, Raoul: "Elementos de la arquitecturar rural en la isla de Ibiza". En A.C. Primer Trimestre 1935, N221. Barcelona; Heilbronner, Erwin: “"biza (Baleares). Las viviendas rurales". En A.C. Primer Trimestre 1935, N 


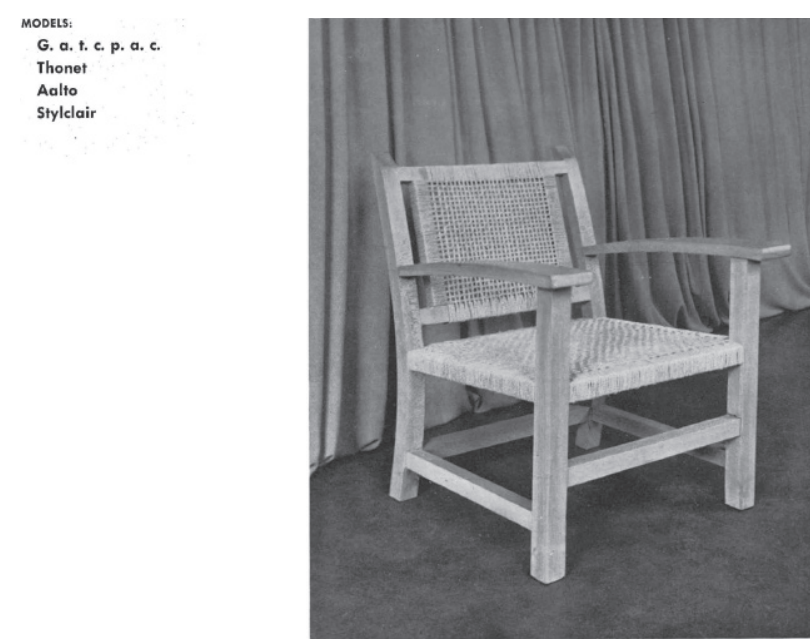

M. I. D. V. A MOBLES I DECORACIÓ DE LA VIVENDA ACTUAT

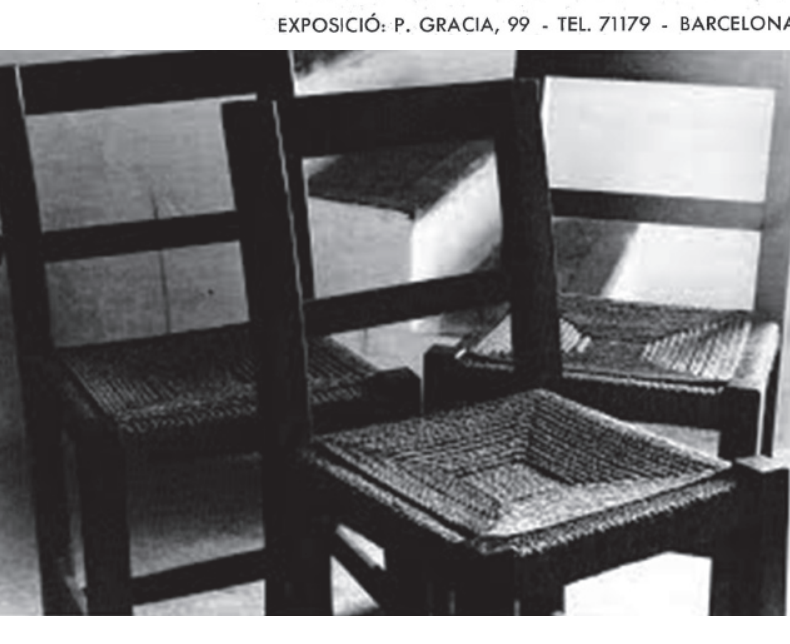

de los muebles que realizaron los arquitectos del grupo. Detectaron en la tradición de este lugar una base primiticos y preindustriales de su nueva estética ${ }^{\prime 34}$. Sus formas
8. Anuncio del M.I.D.V.A. en la revista A.C., fotografía de la silla proyectada por Josep Torres Clave. 9. Fotografía de Raoul Hausmann titulada "Tres sillas".

10. Fotografía del interior del estand del MIDVA para 11. Pabellón de la República de la Exposición Univer sal de 1937 de París. basadas en una obligada austeridad, cautivaron a los arquitectos del grupo, en especial a Josep Torres Clavé. En 1934, este arquitecto diseña un modelo inspirado en la silla tradicional ibicenca, de estructura de madera formada por elementos prismáticos y asiento de cuerda de esparto entrelazado. Partiendo de este sencillo diseño, Tores Clave proyectó la silla Cadirat ${ }^{5}$, una palabra derivada de 'cadira' -nombre genérico con el que se designa . Raimon Tres es aproplada para terraza, fue construida e los mirmos masera de

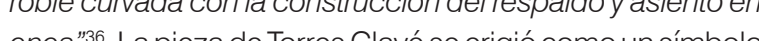
que repestaba as ideas del Gupo Este hasta quer te La silléí insur no sólo encandib́ a To (Tyura 8).

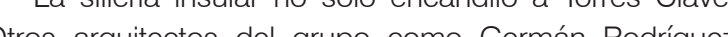

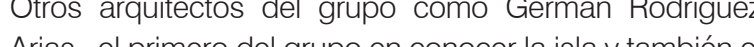
primero pincolo

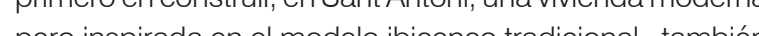

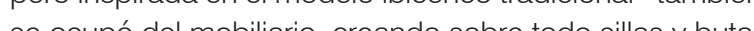
se ocupó dala de pino yenea Conocidos son su bula-

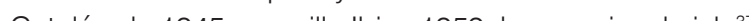
Además, otros in Además, orros intectuales y aristas se quedaron embelésálebre por lajuar no "Tres silla" (figura que tomas ca cilia ibicence Wu "Espacio par o, e caso

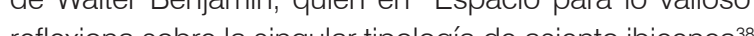

34. Entrevista a Raimon Torres recogida en "La butaca 'Torres Clavé': 75 años de historia". En Diario de lbiza, 16 Enero 2009. Ibiza. 35. Raimon Torres, actual propietario de los derecchos de la butaca que fabrica la casa catalana Mobles 114, afirma que "actualmente se venden unas treinta del trascurso de los años, confirmando las ideas del grupo acerca de la utilidadd de las formas populares: "Se trata de un diseño que no es actual, pero que nunca pasa de moda". İdem.

36. Torres Torres, Raimon, op. cit, p. 19.

37. Cuando Germán Rodríguez Arias se exilióa a Chile, tras l a Guerra Civil, continuó su labor como diseñador de muebles. En 1944 fundó, junto con su cuñado Santiano de Chile las creaciones euroneag, la enpressa Muebles Sur.'. Santiago de Chile, las creaciones europeas yvanguardistas de Rodriguez Arias tuvieron bastante aceptación pors

pretensiones en la forma pero con un mimbre sorprendentemente bello (...). Pero tampoco son únicamente sillas; han cambiaido su función al i isstante, cuando el sombrero cuelgáa encima del respaldo. (...) Valiosas pueden ser sillas y vestidos, cerraduras y alfombras, orzas y cepillos de carpintero. Yel auténtico secreto de su valor es esa sobriedad esa parquedad del espacio vital". Beniamin, Walter: Escritos Autobiográfícos. Madrid: Alianza Universal. 1996. p. 17.
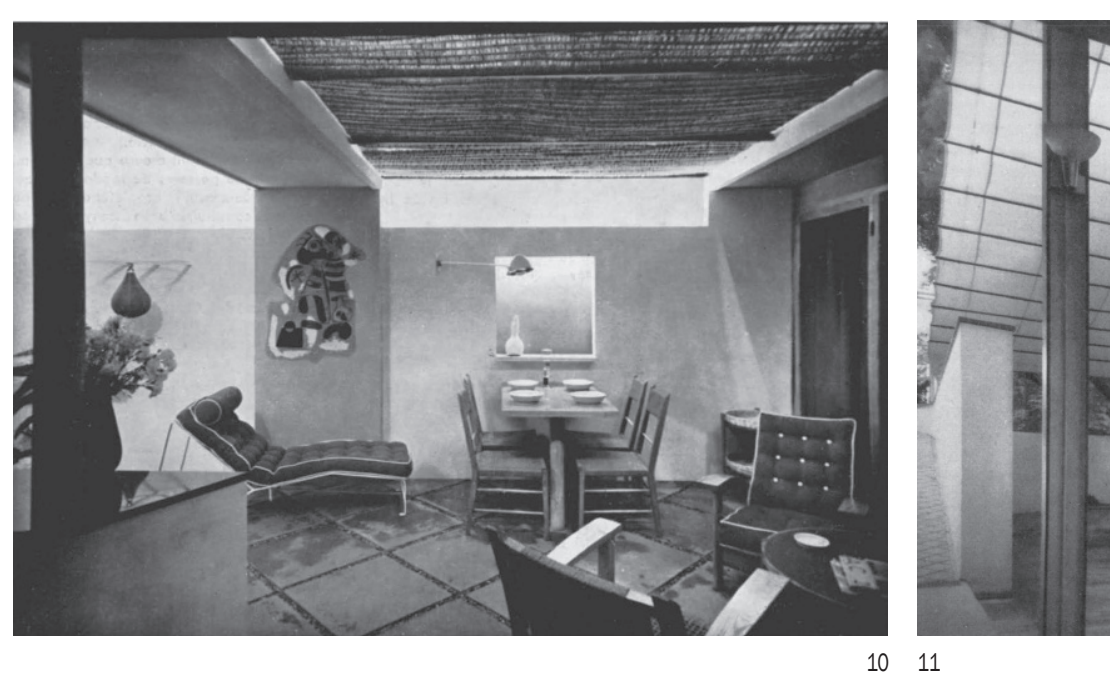

El diseño de Torres Clavé producido por MIDVA ${ }^{39}$ Se convirtio en todo un simbolo de modernidad, a la manera en que la entendía el Grupo Este del GATEPAC. La silla Cadirat fue seleccionada para amueblar el estand de sociedad -MIDVA- del Primer Salón de Decoradores organizado en Barcelona en 1936 por el FAD40 (figura 10) Este acontecimiento que reunió a un gran número de artesanos, técnicos y diseñadores, constituyó para Cataluña -según afirma Mercè Vidal- un paso importante en renovación y consolidación de las artes decorativas y e nacional

Un año después, el modelo de Torres Clavé volvia a ser seleccionado, esta vez para representar a la República, con el objeto de equipar el patio del Pabellón Español de la Exposición Internacional de París de 1937 proyectado por Josep Lluis Sert y Luis Lacasa (figura 11). El amueblamiento de este pabellón fue la última man festación con respecto al mobiliario del GATCPAC, ya que inmediatamente después se produjo el cese de toda actividad debido al ya iniciado conflicto bélico. Para GATEPAC, y más concretamente su Grupo Este la participación en exposiciones fue uno de los aspectos más determinantes en su trayectoria. Tal y como lo exponía la agrupación

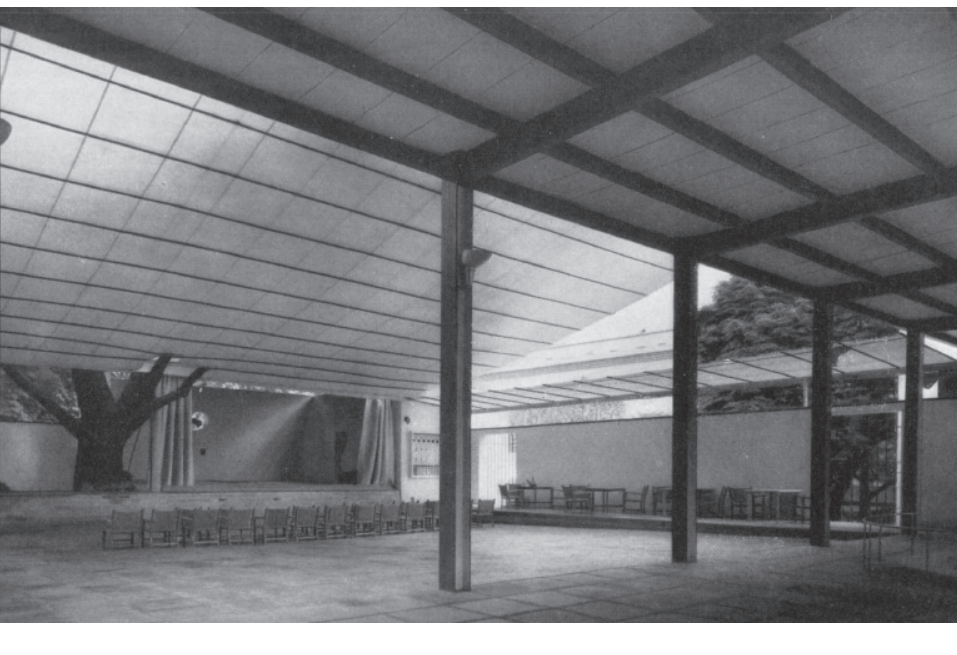

actividades contemporáneas, a base de propaganda"42. mueble, a igua que as exposiciones, las conferencias, los manifiestos, las revistas o los libros, era un elemento mas de propaganda de la nueva arquitectura.

EL ESTÁNDAR DE LA INDUSTRIA POPULAR La naturaleza impersonal de estos objetos artesanales rechazaba la individualidad -entendida como autoafirmación personal- que otorgaba en muchos casos el diseño de ropa y de mobiliario. Parecía una elección equivocada inclinarse por objetos únicos si la tradición había colaborado en producir obras perfeccionadas. El perfil impersonal propio del trabajo artesanal estándar concordaba perfectamente con el rasgo colectivo correspondiente a la evolución cultural y con los procesos de producción contemporáneos. Ese carácter no individualizado procedente de la artesanía tradicional -cuyos muebles se habían perfeccionado a lo largo de los siglos-fue heredado y aplicado para los métodos de producción de aquella época, es decir la producción industrial. Aunque la cualidad intrinseca de la máquina con la que se pretendía crear objetos no individualizados -en los que lo importante era el objeto útil y no el autor o el usuario concreto- se vio corrompida por el protagonismo de varios arquitectos diseñadores de muebles de este tipo.

39. Esta silla se convirtió en la imagenn de la firma como se puede ver en el anuncio publicitario del MIDVA publicado en el número 22 de la revista A.C. 40. GATEPAC: "Primer Salón de decorradores". En A.C. Tercer-cuarto trimestre 1936, N223-24. p.20. A partir de esta colaboración GAACPAC y FAD participaron conjuntamente en la V T Trienal de Milän de 1936 y en la Exposición Internacional de Paris de 1937 . Ap

41. Vidal Jansà, Mercè: "Design history in Catalonia between the influence of Le Corbusier and Mediterranean historical and vernacular sources". En Design

42. GATEPAC: "La evolución del interior". En A.C. 1935, No19. Barcelona. p. 13. 


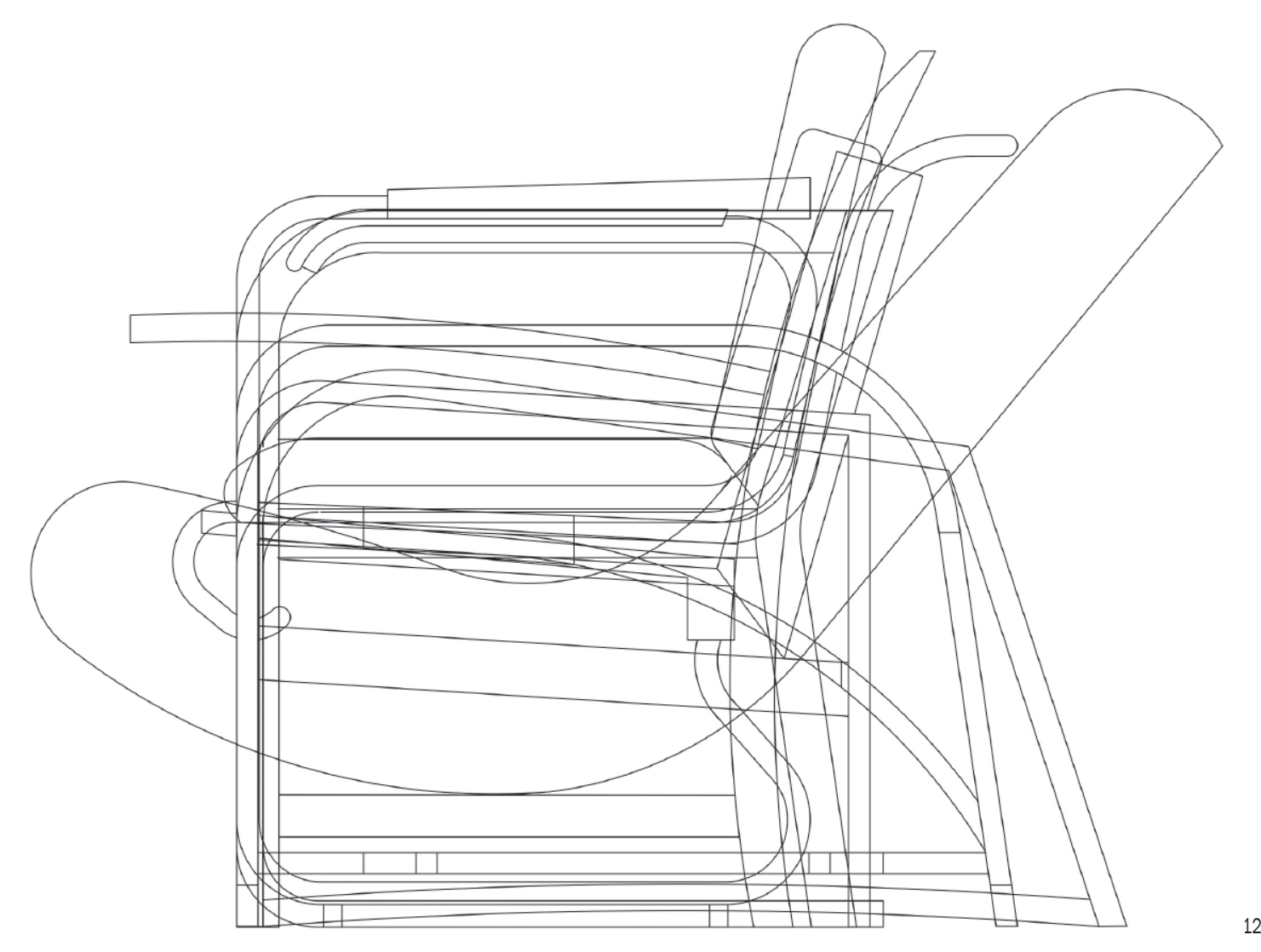

Bibliografía:

Documentos GATEPAC, Arxiu Historicic del Col •legi d'Arquitectes de Catalunya, Barcelona.

Documentos José Manuel Aizpurua y Joaquin Labayen, Archivo Labayen, Tolosa.

Documentos Luis M. Feduchi, Archivo Ignacio Feduchi, Madrid.

"Junco y acero" En Viviendas. Revista del Hogar. 1932, No5. Madrid.

"Lunco y acero". En Viviendas. Revista del Hogar. 1932, No5. Madrid.

"La butaca "Torres Clavé': 75 años de historia". En Diario de lbiza, 16 Enero 2009. Ibiza.

Anibal, Ramón: “Testimonio de Ramón Anibal". En Nueva Forma. 1969, NN40.

Argan, Giulio Carlo: Walter Gropius y el Bauhaus. Buenos Aires: Nueva Visión, 1961.

Benjamin, Walter: Escritos Autobiográficicos. Madrid: Alianza Universal. 1996.

Blasco Castiñeira, Selina: Lis Feduchi 1901-1975, Monoorrafías de arquitectos españoles, Dirección General de Arquitectura, MOPU

Dieckmann, Erich: "Möbelbau”. En Die Baubücher. 1931, No11. Stuttgart: Julius Hoffmann Verlag.

Freixa, Jaume: Josep Luís Sert. Barcelona: Santa \& Cole Ediciones Diseño, ETSAB, 2005.

GATEPAC: "Elementos de la industria popular". En A.C. Documentos de Actividad Contemporánea. Segundo trimestre 1935, NN18. Barcelona.

GATEPAC: "Elementos estándar en el mobiliario: Sillón de madera". En A.C. Documentos de Actividad Contemporánea. Cuarto Trimestre 1931, No4. Barcelona.

GATEPAC: "Joyería Roca, Barcelona". En A.C. Documentos de Actividad Contemporánea. Segundo trimestre 1934, №14. Barcelona.

GATEPAC: "La evolución del interior". En A.C. Documentos de Actividad Contemporánea. Tercer trimestre 1935, No19. Barcelona.

GATEPAC: "Primer Salón de decoradores". En AC. Documentos de Actividad Contemporánea. Tercer-cuarto trimestre 1936, №23-24.

GATEPAC: "Un falso concepto del mobiliario moderno". En A.C. Documentos de Actividad Contemporánea. Tercer trimestre 1934, NN15. Barcelona.

GATEPAC: “Sección de noticias”. En A.C. Documentos de Actividad Contemporánea. Segundo Trimestre 1933, NN10. Barcelona.

Hausmann, Raoul: "Elementos de la arquitectura rural en la isla de Ibiza”. En A.C. Documentos de Actividad Contemporánea. Primer Trimestre 1935, Hausmann, Raoul:
No21. Barcelona.

Esta idea del anonimato derivada del estándar fue te una voluntad por parte de miembros del grupo de sumida por muebles propios No se para aplicarla a la creación de Iuto, sino de un anonimato del autor individul, peva-

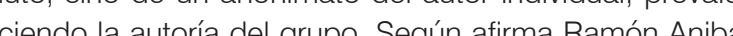
en la revista Nua grupo. Según alim namón Anibal en las que se basaba el grupo con relacín a la alú de sus obras ene "1. incrementar trabajo en equipo, en contra del exacerbado individualismo profesional; 2 . Los trabajos sólo debín aprecer con a sigla GATEPAC 3. Disminir el fuere egocentismo que tan GS ESTag: produce a nuestra profesín en genel,"se

En definitiva la silla dal GATEPAC es el resulado depurado de los distintos modelos que el grupo ideó En el inicio de este desarrollo de piezas exisasumir los principios del mueble moderno a través de fican con la 'imagen' de la modernide, que se identicoan con la "lmagen' de la modemidad en el ámbito del mobilario. Estos fundamentos son asimilados y reproducidos de tal manera que se aplican y adaplan a las formas que ellos consideran modemas, consiruyendo un discurso teorico no virgen, filtrado y propio. Ias for la modenidad por homologacion, reproducen las formas y crean unas nuevas sujelas a los principios de las primeras. La silla del GATEPAC es tomada como modelo estándar que se ajusta al concepto de mobiliario moderno aplicado a los productos de la tradición artecanal Or que es lo mismo, la sila da GatePac es e stria popular (figura 12).

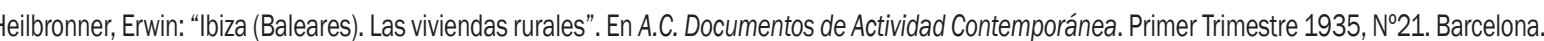
Heilbronner, Erwin, "Establecimiento de baños en la playa de Talamanca, Ibiza (Baleares)". En A.C. Documentos de Actividad Contemporánea. Primer Trimestre 1935, No21. Barcelona.

Mari, Bartomeu: Raoul Hausmann: architecte = architect: Ibiza 1933-1936. Bruxelles: Archives d'architecture moderne, 1990

Subirana i Torrent, Rosa María: "EI mobiliario del GATCPAC. Joan Baptista Subirana i Subirana interiorista y diseñador de muebles". En DC. Revista de critica arquitectónica, 2005, № 13-14. Barcelona: Universidad Politécnica de Cataluña, Departament de Composició Arquitectónica.

Torres Torres, Raimon y otros: Josep Torres Clavé. Barcelona: Santa \& Cole, 1994.

Vidal Jansà, Mercè: "Design history in Catalonia between the influence of Le Corbusier and Mediterranean historical and vernacular sources". En Desiǵn Discourse. 2008, Vol. III No4.

María Villanueva Fernández (Oviedo, 1984), arquitecta por la Universidad de Navarra (2008). Premio Luis Moya Fin de Carrera (2008), con calificación de Matrícula de Honor en el Proyecto Fin de Carrera. Dr. Arquitecto (2012) con la Tesis Doctoral titulada "Equipar en moderno. Mobiliario de arquitectos españoles'. Desde 2008 ha compaginado su labor docente en el departamento de Proyectos de la ETSAUN (2008-2014), en el grado de Ingeniería en Diseño industrial de Tecnun y en el Master de ISEM Fashion Business School (2013-2014) con su trabajo de investigación centrado en el diseño del arquitecto. Ha realizado una estancia de investigación en The Getty Research Institute, Los Angeles (2011) y ha sido visiting scholar en la GSAPP Columbia University (2011).

Héctor García-Diego Villarías (Santander, 1983), arquitecto por la Universidad de Navarra, donde se graduó en 2007 con Premio Extraordinario Fin de Carrera y premio Schindler, además de calificación de Matrícula de Honor en el Proyecto Fin de Carrera. Desde entonces ha desempeñado labores docentes como ayudante en el departamento de Proyectos, al tiempo que ha coordinado el Drestar 


\section{Autor imagen y fuente bibliográfica de procedencia}

Información facilitada por los autores de los artículos: página 18, 1 (GATEPAC, AC Documentos de Actividad Contemporánea, número 4, p. 24$), 2$ (LLOBET, Xavier, 2007 : Hilberseimer y Mies. La metrópolis como ciudad jardín. Barcelona: Fundación Caja de Arquitectos, p. 67); página 19, 3 (GATEPAC, AC Documentos de Actividad Contemporánea, numero 13), 4 (Le Corbusier, [1935] 1964: La ville radieuse. París: Ed. Vincent, p. 34); página 20, 5 (GATEPAC, AC Documentos de Actividad Contemporánea, numero 7), 6 (“КОМИНТЕPHОВСКA", en SA Sovremennaia Arkhitektura, 1930, n. 3); página 22, 7 (VVAA, AC La revista del GATEPAC 1931-1937. Madrid: Museo Nacional de Arte Reina Sofía, p. 203), 8 (TERÁN, Fernando de: Historia del Urbanismo en España: siǵlos XIX y XX. Ed. Cátedra, 1999); página 23, 9 (Archivo fotográfico, Fondo GATEPAC del COAC-Barcelona), 10 (LE CORBUSIER, [1935] 1964: La ville radieuse. París: Ed. Vincent, p. 307); página 27, 1 (Fotografia original cedida por Eduardo Matos (elemento da ODAM)), página 31, 2 (Amorim, Delfim: “A minha casa”. Em RA: Revista de Arquitectura. Outubro 1987, № 0. Porto: Faculdade de Arquitectura da Universidade do Porto), 3 (Losa, Arménio; Barbosa, Cassiano: “Edificio da Carvalhosa”. Em Arquitectura. Revista de Arte e Construção, 2. a série, ano XX. Junho 1953, № 47. Lisboa: s.e.); página 32, 4 (Martins, Luís Oliveira "Habitação para uma família da classe média”. Em RA: Revista de Arquitectura. Outubro 1987, № 0. Porto: Faculdade de Arquitectura da Universidade do Porto); página 33, 5 (Fotografia Edite Rosa. Costa Cabral, F.R.G, “Viana de Lima”, 1953, Porto, Portugal. FAUP/CDUA/Fundo Viana de Lima), 6 ( Fotografia Edite Rosa); página 34, 7 (Fotografia Edite Rosa. Arquivo Histórico Municipal do Porto, processo camarário, licença n¹4 - 8081/51), 8 (Fotografia Edite Rosa), 9 (Pereira da Costa, Francisco: "Imóvel de habitação". Em RA: Revista de Arquitectura. Outubro 1987, № 0. Porto: Faculdade de Arquitectura da Universidade do Porto); página 35,10 (Desenhos cedidos por Cristiano Moreira do Arquivo João Andersen); página 36, 11 (Groupe CIAM Porto, Painel 2. Em Arquitectura. Revista de Arte e Construção, 2. série,

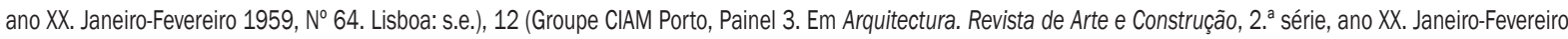
1959, № 64. Lisboa: s.e.); página 37, 13 (Desenho cedido por José Carlos Loureiro), 14 (Fotografia Edite Rosa); página 38, 15 ( Desenhos cedidos por Fernando Távora); página 43, 1 (María Villanueva Fernández, Héctor García-Diego Villarías); página 44, 2 (A.C. Documentos de Actividad Contemporánea); página 45, 3 (Arxiu Històric del Collegi d'Arquitectes de Catalunya); 4 (María Villanueva Fernández, Héctor García-Diego Villarías a partir de Silla Joyería Roca (Museu Nacional d’Art de Catalunya) y sillón Standard (A.C. Documentos de Actividad Contemporánea)); página 46, 5 ( A.C. Documentos de Actividad Contemporánea); página 47, 6 (Viviendas: Revista del hogar), 7 (A.C. Documentos de Actividad Contemporánea); página 48, 8 (A.C. Documentos de Actividad Contemporánea), 9 (Mari, Bartomeu: Raoul Hausmann: architecte = architect: Ibiza 1933-1936. Bruxelles: Archives d'architecture moderne, 1990); página 49, 10 ( A.C. Documentos de Actividad Contemporánea), 11 (Gutmann, Robert; Koch, Alexander: Ausstellungsstände: exhibitionstands. Stuttgart: Koch. 1964); página 50, 12 (María Villanueva Fernández, Héctor García-Diego Villarías); página 54, 1 (Vidotto, Marco: Alison + Peter Smithson, Obras y Proyectos. Barcelona: Gustavo Gili, 2009. @ The Alison and Peter Smithson Archive, Special Collections. Frances Loeb Library, Graduate School of Design. Harvard University, Cambridge), 2 (Louis I. Kahn Collection, Architectural Archives of the University of Pensylvania, no publicado. () Louis I. Kahn Collection. Architectural Archives of the University of Pennsylvania, Philadelphia); página 55, 3 (Van den Heuvel, Dirk; Risselada, Max: Team 10: In Search of a Utopia of the Present. Rotterdam: NAi Publishers, 2005. @ Centre Pompidou Archives, Paris); página 56, 4 (This is tomorrow, Whitechapel Art Gallery, 1956. @ The Alison and Peter Smithson Archive, Special Collections. Frances Loeb Library, Graduate School of Design. Harvard University, Cambridge), página 57, 5 (Brownlee, David, In The Realm of Architecture, Rizzoli, 2005. @ Louis I. Kahn Collection. Architectural Archives of the University of Pennsylvania, Philadelphia), 6 (Woods, Shadrach: The Man in the Street. A Polemic on Urbanism. Londres: Penguin Books, 1975. @ Shadrach Woods Archive. Avery Library Special Collections. Columbia University, New York); página 57, 7 (Curtis, William: Le Corbusier. Ideas and Forms. Londres: Phaidon, 1986. Original en la Fondation Le Corbusier de Paris. @ Fondation Le Corbusier, Paris), 8 (Smithson, Alison y Peter: The Charged Void: Architecture. Nueva York: The Monacelli Press, 2001. @ The Alison and Peter Smithson Archive, Special Collections. Frances Loeb Library, Graduate School of Design. Harvard University, Cambridge); página 60, 9 (Smithson, Alison: Team 10 Primer. Cambridge: MIT Press, 1968. @ The Alison and Peter Smithson Archive, Special Collections. Frances Loeb Library, Graduate School of Design. Harvard University, Cambridge), 10 (Woods, Shadrach: The Man in the Street. A Polemic on Urbanism. Londres: Penguin Books, 1975. @ Shadrach Woods Archive. Avery Library Special Collections. Columbia University, New York), 11 ( Woods, Shadrach: The Man in the Street. A Polemic on Urbanism. Londres: Penguin Books, 1975. @ Shadrach Woods Archive. Avery Library Special Collections. Columbia University, New York); página 61,12 (Smithson, Alison y Peter: The Charged Void: Urbanism. Nueva York: The Monacelli Press, 2005. @ The Alison and Peter Smithson Archive, Special Collections. Frances Loeb Library, Graduate School of Design. Harvard University, Cambridge); página 62, 13 (Ronner, Heinz: Louis I. Kahn: Complete Work 1935-1974. Zurich: Institute for the History and Theory of Architecture, 1987 (primera edición 1977), p. 70. @ Louis I. Kahn Collection. Architectural Archives of the University of Pennsylvania, Philadelphia); página 67, 1 (Fotográfo Jan Versnel. Strauven, Francis: Aldo van Eyck. The Shape of Reality. Ámsterdam: Architectura \& Natura, 1998, p.203), 2 (Créditos fotográficos de Kors van Bennekem. Ligtelijn, Vincent: Aldo van Eyck. Works. Basel: Boston; Berlín: Birkhaüser, 1999, p. 179); página 68, 3 (Stokvis, Willemijn: Cobra. Movimiento artístico internacional de la segunda postǵuerra. Barcelona: Ediciones Polígrafa, S.A., 1987, p.75); página 68, 4 (Stokvis, Willemijn: Cobra. Movimiento artístico internacional de la segunda postguerra. Barcelona: Ediciones Polígrafa, S.A., 1987, p.37), 5 (Créditos fotográficos de Har Oudejans. Ligtelijn, Vincent: Aldo van Eyck. Works. Basel; Boston; Berlín: Birkhaüser, 1999, p.72); página 70, 6 (Créditos fotográficos de la Colección Gemeentemuseum Den Haag. AAVV: Playgrounds, reinventar la plaza. Madrid: Siruela 2014, p.141), 7 (Créditos fotográficos Ámsterdam Fotomuseum. Ligtelijn, Vincent: Aldo van Eyck. Works. Basel; Boston; Berlín: Birkhaüser, 1999. p.105); página 71, 8 (Fotografía de J. D’Oliviera. Ligtelijn Vicent; Strauven, Francis: Aldo van Eyck. Writings. Collected articles and other Writings 1947-1998. Ámsterdam : Sun, cop. 2008, pp.61-78), 9 (Fotografía Violette Cornelius. Strauven, Francis: Aldo van Eyck. The Shape of Reality. Ámsterdam: Architectura \& Natura, 1998, p. 398); página 72, 10 ( Eyck, Aldo van: Projekten 1948-61. Gromingen: Johan van de Beek, 1983, p.80), 11 (Créditos fotográficos Ligtelijn, Vincent: Aldo van Eyck. Works. Basel; Boston; Berlín: Birkhaüser, 1999, p.122), 12 (Fotografía y créditos Aldo van Eyck. Ligtelijn, Vincent: Aldo van Eyck. Works. Basel; Boston; Berlín: Birkhaüser, 1999, p.122); página 73, 13 (Ligtelijn Vicent; Strauven, Francis: Aldo van Eyck writings. The Child, the City and the Artist. Collected articles and other Writings 1947-1998. Ámsterdam : Sun, cop. 2008, p. 131), 14 (Eyck, Aldo van: Projekten 1948-61. Gromingen: Johan van de Beek, 1983, pp.15-17); página 74, 15 (Eyck, Aldo van: Projekten 1948-61. Gromingen: Johan van de Beek, 1983, pp.15-17); página 78, 1 (Archivo Nueva Forma, Biblioteca de la Escuela Técnica Superior de Arquitectura, Universidad de Valladolid); página 79, 2 (Architecture Principe. Febrero 1966, № 1. París. Architecture Principe. Marzo 1966, № 2. París. Portada), 3 (Architecture Principe. Marzo 1966, № 2. París. pp.7-8), 4 
(Archivo Nueva Forma, Biblioteca de la Escuela Técnica Superior de Arquitectura, Universidad de Valladolid); página 80, 5 (Fullaondo, Juan Daniel (Ed.): Claude Parent y Paul Virilio, 1955-1968, arquitectos. Madrid: Alfaguara, 1968. Portada), 6 (Archivo Nueva Forma, Biblioteca de la Escuela Técnica Superior de Arquitectura, Universidad de Valladolid); página 81, 7 (Parent, Claude; Virilio, Paul: “Nevers”. En Nueva Forma. Abril 1968, №27. pp. 44-45), 8 (Archivo Nueva Forma, Biblioteca de la Escuela Técnica Superior de Arquitectura, Universidad de Valladolid); página 82, 9 (Parent, Claude; Virilio, Paul: “Charleville”. En Nueva Forma. Marzo 1968, №26. pp. 66-67); pagina 83, 10 (Colección particular familia Fullaondo-Buigas), 11 (Archivo Nueva Forma, Biblioteca de la Escuela Técnica Superior de Arquitectura, Universidad de Valladolid); página 84, 12 (Nueva Forma. Febrero 1968, № 25. Madrid. p. 77), 13 (Nueva Forma. Febrero 1968, № 25. Madrid. p. 70); página 85, 14 (Archivo Nueva Forma, Biblioteca de la Escuela Técnica Superior de Arquitectura, Universidad de Valladolid); página 87, 15 (Nueva Forma. Julio-agosto 1972, № 78-79); página 92, 1 (Fuente online: Archigram Archival Project http://archigram.westminster.ac.uk/); página 95, 2 (Fuente online: Archigram Archival Project http://archigram.westminster.ac.uk/), 3 (Cook, Peter (Ed.): Archigram. New York: Praeger Publishers, 1973; 26); página 97, 4 (Warren Chalk: "Space Probe!”, Archigram. Op. Cit.; 27. "Okay, Hot-Shot, Okay! I'm Pouring!" (1963). Flickr, galería de cllo2, abril de 2005; Strange Tales no 92 (Marvel Comics, enero de 1962); Mystery in Space nº 74, pág. 6 (DC Comics, marzo de 1962); Mystery in Space n 80, pág. 27 (diciembre de 1962); Magnus Mystery in Space n 86 pág. 8 (DC Comics, septiembre de 1963); Magnus, Robot Fighter n 4 (Gold Key Comics, noviembre de 1963); página 99, 5 (Action Comics nº 203 (DC Comics, abril de 1955), 6 (Mystery in Space nº 86 (DC Comics, septiembre de 1963), 7 (Cook, Peter: Archigram. Op. Cit.; 27); página 100, 8 (Cook, Peter (Ed.): Archigram. New York: Praeger Publishers, 1973; 126-7), 9 ( Amazing Archigram 4, Op. Cit.), 10 (Cook, Peter (Ed.): Archigram; 23); página 102, 11 (VV.AA (Warren Chalk, Peter Cook; Dennis Crompton, Ben Fether, Rae Fether, David Green, Ron Herron, Mike Webb et al): Archigram: Metropolis (otoño de 1964). Página 17 (desplegable)), 12 (Fuente online: Archigram Archival Project http://archigram.westminster.ac.uk/), 13 (Fuente online: Wikimedia Commons), 14 (Fuente online: http://www.lunadude.com/); página 105, 1 ( De derecha a izquierda: AA.W.: La lezione di Aldo Rossi. Bologna: Bononia University Press, 2008, p.141; 2C. Construcción de la Ciudad. Abril 1975, №2. Barcelona: Novographos, 1975, portada; 2C. Construcción de la Ciudad. Octubre 1975, №5. Barcelona: Novographos, 1975, portada; 2C. Construcción de la Ciudad. Diciembre 1979, №14. Barcelona: Novographos, 1979, portada); página 106, 2 (Izquierda, arriba: Archivo Lluís Domènech; abajo: archivo Lluís Clotet; derecha: Arquitecturas Bis. Mayo 1974, №1. Barcelona: La Gaya Ciencia, 1974, portada), página 107, 3 (Mapa: Carolina B. García. Imágenes procedentes de: 2C. Construcción de la ciudad. Junio 1978, №11. Barcelona: Novographos, 1978, p.26; Casanovas, Jordi; Quílez, Francesc M.: El viatge a Espanya d'Alexandre de Laborde (1806-1820). Dibuixos preparatoris. Barcelona: Museu Nacional d'Art de Catalunya, 2006, p. 134; Rossi, Aldo: La arquitectura de la ciudad. Barcelona: Gustavo Gili, 2004, pp. 255, 298, 300); página 108, 4 (Arriba: 2C. Construcción de la ciudad. Junio 1978, №11. Barcelona: Novographos, 1978, p.26; abajo: Ferlenga, Alberto: Aldo Rossi. Architetture 1959-1987. Milano: Electa, 1987, p. 51), 5 (Controspazio. Diciembre 1973, No6. Bari: Edizioni Dedalo. 1973. Portada y p.28); página 110, 6 (AA.WV. Arquitectura racional. Madrid: Alianza Forma, 1979, pp.107, 110, 115, 116), 7 (Izquierda: [En línea, 12 junio 2014]. <http://www.archiexpo.es/prod/ bd-barcelona-design/campanas-extractoras-pared-50941-1246767.html> Derecha: [En línea, 12 junio 2014]. Disponible en internet: http://www.youtube.com/ watch?v=YCV7HK8mmuE); página 111, 8 (Izquierda: Arquitecturas Bis. Noviembre 1974, №4. Barcelona: La Gaya Ciencia, 1974, portada; derecha: Arquitecturas Bis. Enero 1975, №5. Barcelona: La Gaya Ciencia, 1975, portada), 9 (Oppositions. Summer 1976, №5. New York: The Institute for Architecture and Urban Studies, 1976. Portada y página interior); página 112, 10 ( Bescós, Ramón: Bankinter 1972-1977. Edición a cargo de Enrique Granell. Almería: Colegio de Arquitectos de Almería, 1994), 11 (2C Construcción de la Ciudad. Marzo 1977, №8. Barcelona: Novographos, 1977); página 113, 12 (2C. Construcción de la ciudad. Marzo 1977, №8. Barcelona: Novographos, 1977. pp.24-25, 29, 36), 13 (AA.V. Actas del I Seminario Internacional de Arquitectura Contemporánea (SIAC), Santiago de Compostela, 27 septiembre - 9 octubre 1976. Santiago de Compostela: Colegio Oficial de Arquitectos de Galicia, 1976, portada y pp.118-119); página 114, 14 (De izquierda a derecha: Eisenman, Peter; Rossi, Aldo: Aldo Rossi in America: 1976 to 1979. New York: The Institure of the Architecture and Urban Studies, 1979, portada; Rossi, Aldo: The Architecture of the City. Cambridge: Oppositions Books, The MIT Press, 1984, portada; Rossi, Aldo: A Scientific Autobiography. Cambridge: Oppositions Books, The MIT Press, 1981, portada), página 115, 15 (Salvador Tarragó y Lorenzo Soler, fotogramas del film I Seminario Internacional de Arquitectura en Compostela [en línea]. Barcelona: Laboratorios Fotofilm, 1976 [21 junio 2014]. Disponible en internet: < http://vimeo.com/29308522>) 